\title{
Our Experience in the Surgical Treatment of Chronic Constrictive Pericarditis
}

\author{
Ermal Likaj Saimir Kuci Selman Dumani Ali Refatllari \\ Cardiac Surgery Department, University Hospital Centre Mother Theresa, Tirana, Albania
}

\begin{abstract}
Introduction: We reviewed the cases of 21 consecutive patients who underwent surgery for chronic constrictive pericarditis between January 2004 and January 2016, to determine causes, surgical techniques, mortality and morbidity rates, and improvement of functional capacity. Patients and Methods: Eleven of our patients were men $(52.3 \%)$ and ten were women (47.7\%); their average age was $48.71 \pm 15.6$ years. The pericarditis was tuberculous in 13 patients $(61.9 \%)$, idiopathic in 4 patients $(19 \%)$, rheumatic in two patients $(9.5 \%)$, post surgical in one patient (4.75\%) and neoplastic in one patient (4.75\%). Results: In all the cases, our approach was median sternotomy. All anterior pericardium was resected from left phrenic nerve to right phrenic nerve. No patient required cardiopulmonary bypass. We had no early postoperative mortality. In the 1st postoperative month, functional capacity improved dramatically: the number of patients in New York Heart Association functional class IV moved from 13 (preoperatively) to 4; in class III, from 7 to 3 ; in class II, from 1 to 6 ; and in class I, from 0 to 10 . Conclusions: We recommend the median sternotomy approach for chronic constrictive pericarditis. Tuberculosis still remains the main cause at our country. It can be treated with excellent results nowadays.
\end{abstract}

Keywords: surgical treatment, chronic constrictive pericarditis

DOI: $10.7176 / \mathrm{JMPB} / 68-03$

Publication date:September $30^{\text {th }} 2020$

\section{Introduction}

The clinical features of chronic constrictive pericarditis (CCP) were first described in 1842 by Cheever in his Observations on the Diseases of the Orifice and Valves of the Aorta. Constrictive pericarditis (CP) is a disease characterized by the encasement of the heart by a rigid non-pliable pericardium due to dense fibrosis and adhesions. This causes impaired diastolic cardiac function leading to heart failure manifested as systemic without pulmonary congestion.

Today, pericardio-ectomy is a safe procedure with available techniques. In this retrospective study of 21 consecutive cases at our hospital, we investigated the causal factors of CCP, surgical techniques, morbidity and mortality rates, and improvement in functional capacity after discharge.

\section{Patients and Methods}

We reviewed the cases of 21 consecutive patients who underwent surgery for chronic constrictive pericarditis between January 2004 and January 2016. Eleven of our patients were men (52.3\%) and ten were women (47.7\%); their average age was $48.71 \pm 15.6$ years. The pericarditis was tuberculous in 13 patients $(61.9 \%)$, idiopathic in 4 patients $(19 \%)$, rheumatic in two patients $(9.5 \%)$, post surgical in one patient $(4.75 \%)$ and neoplastic in one patient $(4.75 \%)$.

\begin{tabular}{|l|c|c|}
\hline Etiology & Number & Percentage \\
\hline Tuberculosis & 13 & 61.9 \\
\hline Rheumatic & 2 & 9.5 \\
\hline Post surgical & 1 & 4.75 \\
\hline Neoplastic & 1 & 4.75 \\
\hline Idiopathic & 4 & 19 \\
\hline
\end{tabular}

Table 1. Etiology

The most common clinical signs related to cardiac failure were dyspnea, fatigue, hepatomegaly and peripheral edema. Other clinical features are shown in the following table. 


\begin{tabular}{|l|c|c|}
\hline Sign & Number & Percentage \\
\hline Dyspnea & 21 & 100 \\
\hline Pain & 4 & 19 \\
\hline Fever & 1 & 4.7 \\
\hline Fatigue & 16 & 76.2 \\
\hline Hepatomegaly & 16 & 76.2 \\
\hline Edema & 8 & 38 \\
\hline Arrhythmias(AF) & 6 & 28.5 \\
\hline
\end{tabular}

\section{Table 2. Clinical signs}

Diagnosis was made based on the clinical and imaging data. Echocardiography and computed tomography gave important information regarding pericardial constriction and morphology. Some of the patient underwent catheterization of the heart to confirm the diagnosis with deep plateau sign. Data obtained from echocardiography are shown in the following table.

\begin{tabular}{|l|c|c|}
\hline Sign & Number & Percentage \\
\hline Effusion & 9 & 42.8 \\
\hline Calcifications & 3 & 14.2 \\
\hline Twisting of the septum & 15 & 78.9 \\
\hline High echogenicity & 19 & 90.4 \\
\hline
\end{tabular}

\section{Table 3. Echocardiography data}

It is also important to emphasize the diagnostic value of the routine imaging methods like chest $\mathrm{x}$ ray. In the following image we present the case of a young lady who was hospitalized for renal failure with peripheral edema. On lateral chest $\mathrm{x}$ ray was noted a typical pericardial constriction following tuberculosis.

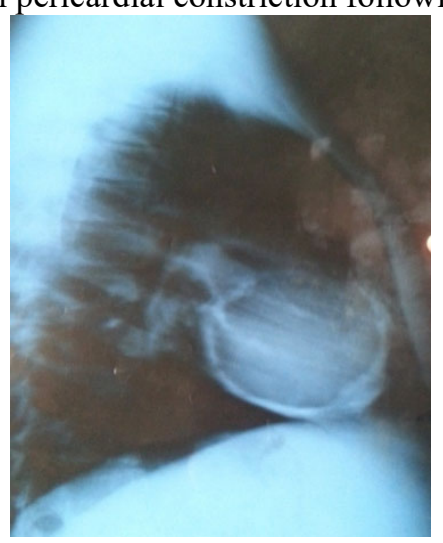

Figure 1. Lateral chest $\mathrm{x}$ ray of a young woman with constrictive pericarditis

\section{Results}

\section{Surgical technique}

In all patients, we approached via median sternotomy. We freed the pericardium in this order: first from the aorta and pulmonary artery, including the left ventricular outflow tract; then from the left and right ventricles and the left pulmonary vein orifices; and finally from the superior and inferior venae cava. To avoid damage to the phrenic nerves, we surgically resected the entire anterior pericardium, within 1 or $2 \mathrm{~cm}$ of the phrenic nerves, then completed the dissection of the pericardium from the diaphragm.

In 7 patients with calcific pericardial plaques, we could not develop a cleavage plane, so we left small islands of plaques in place, reducing their size and relieving constriction by means of wedge incisions that reached the epicardium.

During the procedure we lowered the amplitude of the cautery to avoid causing diathermal dysfunction of the 
right ventricle during electrocauterization. None of the 21 patients experienced ventricular fibrillation, so there was no need for cardioversion. No patient required cardiopulmonary bypass.

\section{Complications and mortality}

Postoperative complications were infection, low cardiac output, acute renal failure, and acute respiratory failure. We had no early postoperative mortality. In the 1st postoperative month, functional capacity improved dramatically: the number of patients in New York Heart Association functional class IV moved from 13 (preoperatively) to 4; in class III, from 7 to 2; in class II, from 1 to 6; and in class I, from 0 to 9 .

\begin{tabular}{|l|c|c|}
\hline Complication & Number & Percentage \\
\hline Low cardiac output & 1 & 4.7 \\
\hline Respiratory failure & 2 & 9.5 \\
\hline Renal failure & 1 & 4.7 \\
\hline Infection & 1 & 4.7 \\
\hline
\end{tabular}

Table 4. Postoperative complications

\begin{tabular}{|c|c|c|}
\hline NYHA class & Preoperatively & Postoperatively \\
\hline IV & 13 & 4 \\
\hline III & 7 & 2 \\
\hline II & 1 & 6 \\
\hline I & 0 & 9 \\
\hline
\end{tabular}

Table 5. Functional capacity improvement after the operation

\section{Discussion}

Regarding the etiology of constrictive pericarditis, tuberculosis is the most frequent cause in our series of patients. Fibrosis and calcification can extend very severely in tuberculosis patients, and this is the primary reason to perform the operation as early as possible. Chronic constrictive pericarditis of more than a year in duration decreases the success rate of surgery and increases the mortality rate (1). Chronic constrictive pericarditis after open-heart surgery was reported first in 1972 by Kendall (2). The development period for constrictive pericarditis after coronary artery bypass averages 2 years. Fewer than 5\% of CCP cases are caused by surgery (3). The number of cases of CCP caused by mediastinal radiotherapy has increased in recent years. The development period is between 8 and 16 months. Cardiopulmonary bypass is necessary because of severe attachments (4).

The overall survival after pericardiectomy for CP differs significantly among the major etiologic subgroups. The best for patients with idiopathic and miscellaneous constriction, intermediate for postsurgical constriction and poor for postradiation constriction (5).

Bilateral thoracotomy, left anterior thoracotomy, and median sternotomy are all the approaches that can be used in treating CCP. The sternotomy incision enables exploration of the left ventricle and right part of the heart and direct vision of the great vessels. It is possible to perform an extensive pericardiectomy with minimal cardiac manipulation. Further advantages of the median sternotomy are the ease and comfort of this approach for the surgeon, the ability to initiate CPB if necessary.

In some cases of CCP surgery, the importance of CPB is evident. If there is a calcific and thickened pericardial fragment without a cleavage plane, it can be left in place; but if the surgeon wants to excise the thickened part, $\mathrm{CPB}$ should be performed. Concomitant procedure like CABG and valve surgery make mandatory the usage of cardiopulmonary bypass. Large series have shown that CPB does not place the patient at serious risk for early death or severe complications. If there is low cardiac output before the operation, primary treatment with catecholamine infusions should be started before the operation. In unresponsive cases, an intraaortic balloon pump can be tried.

We had no perioperative mortality in our series. The usual perioperative mortality after surgery for constrictive pericarditis is around $5 \%$ in recent studies $(5,6,7)$. The most frequent cause of death in the perioperative period was low-output heart failure. Perioperative mortality appears to be related to etiology, being higher for postradiation and postsurgical constriction. This is probably related to the fact that constriction is not the sole factor producing cardiac failure in these subgroups. 
Conclusions: We recommend the median sternotomy approach for chronic constrictive pericarditis. Tuberculosis still remains the main cause at our country. It can be treated with excellent results nowadays.

\section{References}

1.Shabetai R. Pericardial diseases. In: Hurst JW, editor. The heart, arteries and veins. New York: McGraw-Hill; 1990. p. 1348-74.

2.Kendall ME, Rhodes GR, Wolfe W. Cardiac constriction following aorta-to-coronary bypass surgery. J Thorac Cardiovasc Surg 1972;64:142-53.

3.Killian DM, Furiasse JG, Scanlon PJ, Loeb HS, Sullivan HJ. Constrictive pericarditis after cardiac surgery. Am Heart J 1989;118:563-8.

4.DeValeria PA, Baumgartner WA, Casale AS, Freene PS, Cameron DE, Gardner TJ, et al. Current indications, risks, and outcome after pericardiectomy. Ann Thorac Surg 1991; 52(2):219-24.

5.Stefan C. Bertog, Senthil K. Thambidorai, Kapil Parakh, Paul Schoenhagen, Volkan Ozduran, Penny L. Houghtaling, Bruce W. Lytle, Eugene H. Blackstone, Michael S. Lauer, Allan L. Klein. Constrictive Pericarditis: Etiology and Cause-Specific Survival After Pericardiectomy. JACC Vol. 43, No. 8, 2004 April 21, 2004:1445-52

6. Ling LH, Oh JK, Schaff HV, et al. Constrictive pericarditis in the modern era: evolving clinical spectrum and impact on outcome after pericardiectomy. Circulation 1999;100:1380-6.

7. Omoto T, Minami K, Varvaras D, Bothig D, Korfer R. Radical pericardiectomy for chronic constrictive pericarditis. Asian Cardiovasc Thorac Ann 2001;9:286-90. 